\title{
Schmallenberg virus challenge models in cattle: infectious serum or culture-grown virus?
}

Kerstin Wernike ${ }^{1}$, Michael Eschbaumer ${ }^{1,3}$, Angele Breithaupt ${ }^{2,4}$, Bernd Hoffmann $^{1}$ and Martin Beer ${ }^{1 *}$

\begin{abstract}
Schmallenberg virus (SBV), discovered in Europe in 2011, causes mild transient disease in adult ruminants, but fetal infection can lead to severe malformation in cattle, sheep and goats.

To elucidate the pathogenesis of this novel orthobunyavirus, considerable efforts are required. A reliable and standardized infection model is essential for in vivo studies. In the present study, two groups of four cattle were inoculated with either serum passaged in cattle only or cell culture-grown virus. The replication of culture-grown SBV in cattle was reduced compared to virus inoculated via infectious serum. In a second experiment, the infectious serum was titrated in calves; the tested batch contained $10^{2.83}$ infectious doses per $\mathrm{mL}$. Hence, serum-borne virus that was only passaged in the natural host is a suitable option for a standardized SBV infection model.
\end{abstract}

\section{Introduction}

In 2011, Schmallenberg virus (SBV), an orthobunyavirus related to viruses of the Simbu serogroup, was discovered in Germany [1,2]. In adult cattle, SBV infection is associated with mild transient disease, but it can lead to severe fetal malformations when pregnant cows and ewes are exposed in early to mid pregnancy [3]. Currently, the knowledge about SBV is very limited; a reliable and highly standardized infection model is required to elucidate its pathogenesis and to test potential vaccines.

To this end, the present study compares the induction and progression of viremia in cattle for the two different inocula, (i) an SBV field strain that was only passaged in cattle (delivered as infectious serum) as well as (ii) virus grown in tissue culture for a maximum of 4 passages. In addition, the infectious serum was titrated in calves to quantify its infectivity.

\section{Materials and methods}

All experimental protocols were reviewed by a state ethics commission and have been approved by the competent authority (State Office for Agriculture, Food Safety and Fisheries of Mecklenburg-Vorpommern, Rostock,

\footnotetext{
* Correspondence: martin.beer@fli.bund.de

${ }^{1}$ Institute of Diagnostic Virology, Friedrich-Loeffler-Institut (FLI), Suedufer 10, Greifswald, Insel Riems 17493, Germany

Full list of author information is available at the end of the article
}

Germany, ref. LALLF M-V TSD/7221.3-1.1-004/12). All animals were between 9 and 18 month of age.

\section{Infectious serum as inoculum}

In a previous study, a single calf had been subcutaneously inoculated with blood samples from four diseased cattle [1] of the same outbreak series that were positive in an SBV real-time quantitative reverse transcription PCR (RT-qPCR). EDTA-treated whole blood, taken from this calf 4 days after infection (dpi) was subcutaneously injected into two further calves (C01, C02). Both inoculated animals were PCR-positive for the first time at $2 \mathrm{dpi}$, and one developed diarrhea for several days. Half a liter of serum from each calf was collected at $3 \mathrm{dpi}$, divided into portions of $1 \mathrm{~mL}$ and stored at $-70^{\circ} \mathrm{C}$ until it was used in the subsequent experiments.

The sera contained $2.0 \times 10^{3}$ and $1.3 \times 10^{3} 50 \%$ tissue culture infectious doses per $\mathrm{mL}\left(\mathrm{TCID}_{50} / \mathrm{mL}\right)$, respectively, as determined by end-point titration on baby hamster kidney (BHK) cells (cell line L0164, Collection of Cell Lines in Veterinary Medicine, Friedrich-LoefflerInstitut, Insel Riems, Germany). Both sera were tested free of any bacterial contamination. Using sensitive realtime PCR protocols, it could be shown that they did not contain detectable nucleic acids of bovine herpesvirus type 1 [4], pestiviruses [5], Rift Valley fever virus [6], bluetongue virus, foot-and-mouth disease virus or epizootic hemorrhagic disease virus (unpublished assays). 


\section{Cell culture supernatant as inoculum}

SBV was isolated from the blood of an infected cow as previously described [1]. After initial isolation on $\mathrm{KC}$ cells (cell line L1062; derived from Culicoides variipennis midges [7]) the virus was passaged in BHK cells, then in $\mathrm{KC}$ and again in BHK cells. The infectivity was determined by end-point titration on BHK cells.

\section{Animal experiments \\ Comparison between infectious serum and cell culture supernatant}

Twelve SBV-naive calves were assigned to three groups of four animals each. Calves in group 1 (C03-C06) were subcutaneously injected with $1 \mathrm{~mL}$ of serum obtained from $\mathrm{C} 01$, while calves in group 2 (C07-C10) received $2 \times 10^{7} \mathrm{TCID}_{50}$ of culture-grown virus. Animals in group 3 (C11-C14) were injected with phosphatebuffered saline (PBS) and kept as controls.

Following the inoculation, the animals were monitored for the presence of clinical signs every day, rectal body temperatures were measured daily and serum samples were taken daily during the first eight days and weekly thereafter. RNA was extracted using the MagNA Pure LC Total Nucleic Acid Isolation Kit for automated extraction (Roche Diagnostics Deutschland $\mathrm{GmbH}$, Mannheim, Germany) according to the manufacturer's recommendations. SBV genome load in the samples was determined by S segment-specific RT-qPCR as described previously [8] with an external standard based on the $S$ genome segment; at its peak, the difference between the groups was statistically evaluated with a $t$-test. Serological data was collected at weekly intervals using a commercially available ELISA kit (ID Screen ${ }^{\circledR}$ Schmallenberg virus Indirect ELISA kit, IDvet, Montpellier, France). A diverse panel of tissue samples (e.g. lymphnodes, spleen) was taken at necropsy on days 24 or 25 ; they were homogenized and tested for the presence of SBV RNA by RT-qPCR.

\section{In vivo titration of infectious serum}

In a subsequent in vivo titration experiment two calves received the undiluted serum of C01 (group A, C15C16), while groups of three calves each were given dilutions of $1 / 10$ (group B, C17-C19), 1/100 (group C, C20-C22) and 1/1000 (group D, C23-C25) in sterile PBS, respectively. Serum samples were taken at days 1 to 7 and 21; they were tested for SBV RNA and SBVspecific antibodies as described above.

\section{Results}

\section{Comparison of cell culture supernatant and infectious} serum as inoculum

In the samples taken 2 days after infection, all cattle, either inoculated with infectious serum (group 1) or culture-grown virus (group 2), scored positive in the RTqPCR for the first time. SBV genome remained detectable until day 5 in two out of four animals in group 1, until day 6 in the remaining two calves in group 1 and the three animals in group 2, whereas in the last calf in group 2 SBV genome was detected until day 7 (Figure 1). At peak RNAemia (4 dpi), there was no significant difference between the SBV RNA loads in groups 1 and 2 $(p=0.14$, power $=0.519)$.

SBV RNA was not detected in the control animals at any time. Fever was not observed in any animal, but C08 developed mild diarrhea for two days.

Necropsy of the animals did not reveal any significant gross pathomorphological lesions. The mesenteric lymph nodes of $\mathrm{C} 03$ and $\mathrm{C} 06-\mathrm{C} 08$ were positive in the RTqPCR (average Cq value: $34.8 \pm 5.2$ ). In addition, SBV RNA was found in the mandibular lymph nodes of C04 and C06 (Cq values: 39.0, 37.8), and the spleens of C05 and C06 (Cq values: 44.5, 36.9).

All cattle in group 1 and 2 were positive in the ELISA two weeks after infection, while all in-contact animals remained negative until the end of the study (data not shown).

\section{In vivo titration of the infectious serum}

In the in vivo titration experiment, both animals inoculated with the undiluted serum $(\mathrm{C} 15 / \mathrm{C} 16)$, as well as C17 (group B, 1/10), scored positive in the RT-qPCR between day 2 and 5. In C18 and C19 SBV genome was detectable for the first time on day 3 . Animals in group $C$ $(1 / 100)$ scored positive on days 2 to 6,4 to 7 and 3 to 7 , respectively. In the group inoculated with dilution $1 / 1000$ only one (C25) out of three animals was positive (Figure 2). Hence, the undiluted serum contained at least

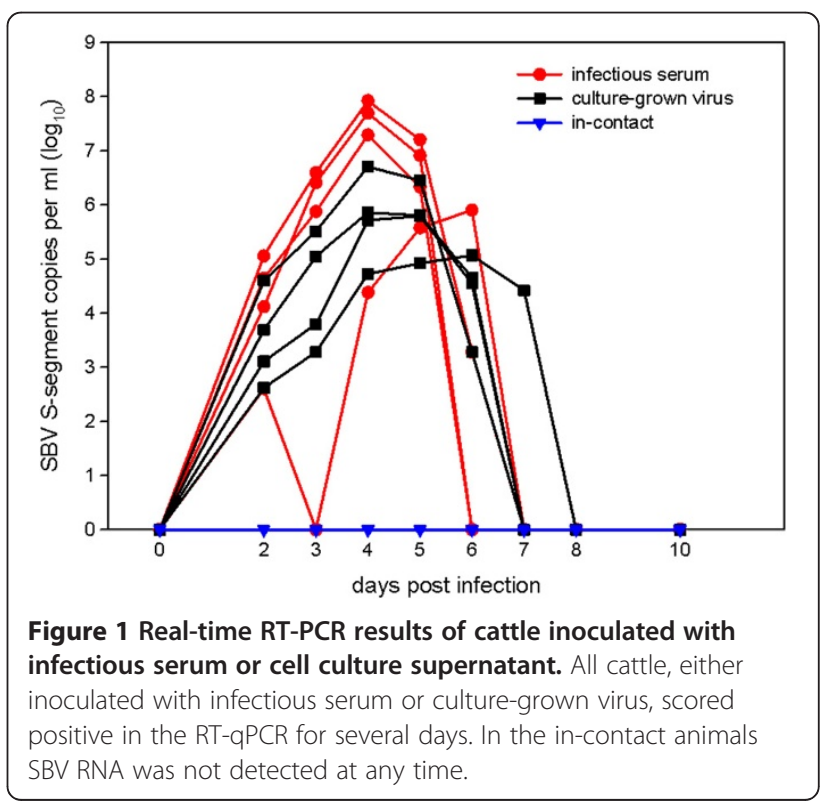




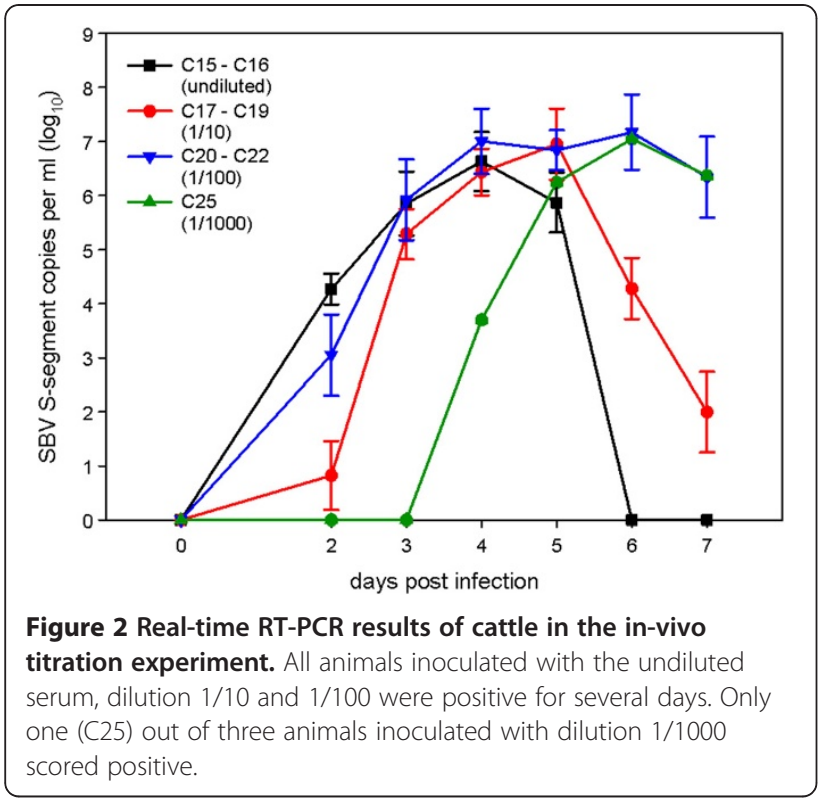

$10^{2.83}$ cattle infectious doses per $\mathrm{mL}$ (calculated by Spearman-Karber method). All cattle with positive RTqPCR results (groups A, B, C and C25) seroconverted in the ELISA (data not shown). The mesenteric lymph nodes of these animals were positive in the RT-qPCR as well (average $\mathrm{Cq}$ value: $32.1 \pm 2.4$ ). Additionally, SBV RNA was detected in the mandibular lymph nodes of C16 C20, C22 and C25 (36.3 \pm 3.3$)$, the spleens of C17, $\mathrm{C} 20$ and $\mathrm{C} 22(39.6,37.7,44.8)$ and the tonsil of $\mathrm{C} 19$ (38.1).

\section{Discussion}

The reliable induction of viremia is an important feature of challenge models for vector-borne diseases [9]. When viruses are passaged in cell culture, however, the positive selection of spontaneous mutations that promote replication in this environment can lead to changes in virus phenotype, including a reduced replication efficiency and virulence in the natural hosts. This has been demonstrated for several bunyaviruses $[10,11]$ and is commonly exploited for the production of AKAV vaccines [12]. The genome stability of vector-borne viruses grown in culture can be promoted by switching between cell lines of mammalian and insect origin (mimicking natural host alternation) [13], but pertinent data for bunyaviruses are not available. In the present study, the replication of culture-grown SBV in cattle was reduced compared to a strain that had only been passaged in the natural host. While not statistically significant within the constraints of this experiment (small group size, high variability within groups), this difference provides a clear indication of the pitfalls of culture-based production of challenge inocula. The high level of infectivity in the tested serum batch offsets one of the major advantages of culture-grown viruses, namely the easier availability of large amounts of material. Based on our findings, cattle-derived infectious serum is a viable and robust option for a standardized SBV infection model, which is required for vaccine evaluation and pathogenesis studies.

\section{Competing interests}

The authors declare that they have no competing interests.

\section{Authors' contributions}

Conceived and designed the experiments: KW ME BH MB. Performed the experiments: KW ME AB BH. Analyzed the data: KW ME AB. All authors read and approved the final manuscript.

\section{Acknowledgements}

Patrick Zitzow and Anja Landmesser rendered outstanding technical assistance. Dedicated animal care was provided by the staff of the isolation unit of the FLI. We are also grateful to Matthias Lenk from the cell culture collection for veterinary medicine of the FLI for his continuous support. This work was financially supported by Boehringer Ingelheim Pharma GmbH \& CO. KG.

\section{Author details}

${ }^{1}$ Institute of Diagnostic Virology, Friedrich-Loeffler-Institut (FLI), Suedufer 10, Greifswald, Insel Riems 17493, Germany. ${ }^{2}$ Department of Experimental Animal Facilities and Biorisk Management, Friedrich-Loeffler-Institut (FLI), Suedufer 10, Greifswald, Insel Riems 17493, Germany. ${ }^{3}$ Faculty of Veterinary Medicine, University of Calgary, Calgary, Canada. ${ }^{4}$ Present address: Department of Veterinary Pathology, Faculty of Veterinary Medicine, Freie Universität Berlin, Berlin, Germany.

Received: 18 September 2012 Accepted: 14 November 2012 Published: 11 December 2012

\section{References}

1. Hoffmann B, Scheuch M, Höper D, Jungblut R, Holsteg M, Schirrmeier H, Eschbaumer M, Goller KV, Wernike K, Fischer M, Breithaupt A, Mettenleiter TC, Beer M: Novel orthobunyavirus in cattle, europe, 2011. Emerg Infect Dis 2012, 18:469-472.

2. Goller KV, Höper D, Schirrmeier H, Mettenleiter T, Beer M: Schmallenberg virus as possible ancestor of shamonda virus. Emerg Infect Dis 2012, 18:1644-1646.

3. Conraths FJ, Peters M, Beer M: Schmallenberg virus: a novel orthobunyavirus infection emerging in ruminants in Europe: Potential global impact and preventive measures. N Z Vet J 2012, doi:doi:10.1080/ 00480169.2012.738403.

4. Wernike K, Hoffmann B, Kalthoff D, Konig P, Beer M: Development and validation of a triplex real-time PCR assay for the rapid detection and differentiation of wild-type and glycoprotein E-deleted vaccine strains of Bovine herpesvirus type 1. J Virol Methods 2011, 174:77-84.

5. Hoffmann B, Depner K, Schirrmeier H, Beer M: A universal heterologous internal control system for duplex real-time RT-PCR assays used in a detection system for pestiviruses. J Virol Methods 2006, 136:200-209.

6. Drosten C, Gottig S, Schilling S, Asper M, Panning M, Schmitz H, Gunther S: Rapid detection and quantification of RNA of Ebola and Marburg viruses, Lassa virus, Crimean-Congo hemorrhagic fever virus, Rift Valley fever virus, dengue virus, and yellow fever virus by real-time reverse transcription-PCR. J Clin Microbiol 2002, 40:2323-2330.

7. Wechsler SJ, MCHolland LE, Wilson WC: A RNA virus in cells from Culicoides variipennis. J Invertebr Pathol 1991, 57:200-205.

8. Bilk S, Schulze C, Fischer M, Beer M, Hlinak A, Hoffmann B: Organ distribution of Schmallenberg virus RNA in malformed newborns. Vet Microbiol 2012, 159:236-238.

9. Eschbaumer $M$, Wäckerlin R, Rudolf $M$, Keller M, Konig P, Zemke J, Hoffmann B, Beer M: Infectious blood or culture-grown virus: a comparison of bluetongue virus challenge models. Vet Microbio/ 2010, 146:150-154. 
10. Griot C, Gonzalez-Scarano F, Nathanson N: Molecular determinants of the virulence and infectivity of California serogroup bunyaviruses. Annu Rev Microbiol 1993, 47:117-138.

11. Lundkvist A, Cheng Y, Sjolander KB, Niklasson B, Vaheri A, Plyusnin A: Cell culture adaptation of Puumala hantavirus changes the infectivity for its natural reservoir, Clethrionomys glareolus, and leads to accumulation of mutants with altered genomic RNA S segment. J Virol 1997, 71:9515-9523.

12. Ogawa $\mathrm{Y}$, Kato $\mathrm{K}$, Tohya $\mathrm{Y}$, Akashi H: Characterization of temperaturesensitive Akabane virus mutants and their roles in attenuation. Arch Virol 2007, 152:1679-1686.

13. Moutailler S, Roche B, Thiberge JM, Caro V, Rougeon F, Failloux AB: Host alternation is necessary to maintain the genome stability of rift valley fever virus. PLoS Negl Trop Dis 2011, 5:e1156.

doi:10.1186/1297-9716-43-84

Cite this article as: Wernike et al.: Schmallenberg virus challenge models in cattle: infectious serum or culture-grown virus?. Veterinary Research 2012 43:84

\section{Submit your next manuscript to BioMed Central and take full advantage of:}

- Convenient online submission

- Thorough peer review

- No space constraints or color figure charges

- Immediate publication on acceptance

- Inclusion in PubMed, CAS, Scopus and Google Scholar

- Research which is freely available for redistribution 